\title{
A Teaching Methodology for Parametric Design: A Case Study with Parametric Bench
}

\author{
Asli Agirbas \\ Fatih Sultan Mehmet Vakif University, Istanbul | Turkey | asliagirbas@gmail.com
}

\begin{abstract}
In parametric design-oriented elective courses given in the architecture departments, most of the parametric designs generally remain at the modeling stage and cannot pass to the design application stage. In this study, this situation was determined as a research problem. Therefore, an experimental method within the scope of the parametric design course was considered. The applied method was discussed and the result product was evaluated. The applied method not only overcame the research problem, but also helped students to develop creativity and collaborative competency.
\end{abstract}

Keywords: Parametric design; Digital fabrication; Architectural education; Teaching methodology; Undergraduate programme.

\section{INTRODUCTION}

Today, parametric design comes to the fore in the field of design. Students demand to learn parametric design tools during their undergraduate education. Therefore, relevant courses are included in undergraduate programs. However, the parametric modeling in the courses cannot go through the application stage, because the lesson hours are limited and the course is carried out separately from the architectural design studio course. Considering this situation, a method proposal for elective courses has been introduced in this study.

\section{BACKGROUND}

\section{PARAMETRIC DESIGN AND EDUCATION}

Computer software has a very important place in the field of architecture as it can easily produce forms suitable for contemporary architectural forms, it can produce fast and various form alternatives, and it can easily produce complex geometries that cannot be drawn by hand. Computer software has taken its place in the world of architecture with its use both in the field of education and in the sector.

However, computer software is developing very rapidly, and the number of computer software is increasing very quickly. The features and interfaces of each software are different. Each software can have a different input in the design process. In fact, each software can have different effects on design thinking. For these reasons, researchers carried out studies on the inclusion of these software in education.
There are studies on the use of parametric design tools in architectural education. For example, Celani and Vaz (2012) compared the use of scripting languages and visual programming languages in architectural education. Aish and Hanna (2017) evaluated undergraduate students' learning curves with using different parametric systems. Agirbas (2018) conducted an experimental study on the use of metaphors in parametric design education. In addition, studies investigating the use of parametric design tools in architectural education and its effect on design thinking are also being researched (Schnabel, 2012; Oxman, 2017).

\section{DIGITAL SKETCH}

Almost every branch in the field of design and art begins to design with sketching. While designers sketch on paper they revise and refine their ideas by observation and visual documentation (Schon, 1983, Schon, 1987, Schon, 1988). In this process, designers make conceptualization, modification and refinement (Cross, 1982; Cross, 2006; Cross, 2011). Sketching is an iterative process in which designers continuously develop the design idea (Garner, 1992; Schon and Wiggins, 1992; Goel, 1995; Gross and Do, 1996; Suwa and Tversky, 1996; Do et. al, 2001; Suwa and Tversky, 2002, Goldschmidt and Smolkov, 2006). In this process, designers are not fully focused on the design outcome. They focus more on the process and this may lead to a very different point from where they started designing. Therefore, this is not a linear process. Goel (1992) defines this process as ill-structured process. Bhoosham (2017) also emphasizes that the cognitive model of design thinking is not a linear process, so the sketching process is an important process. 
Inevitably, the designer reinterprets the visual documentation that he created. So, he gets self-feedback. The sketching process is actually a process that has full of surprises. When the designer sees his new drawing, other things come to mind and the designer drifts to new ideas. This can be sometimes developed even with a line that the designer has accidentally drawn. Another commonly used sketching method is to make a model. When the designer makes a model of his design, he can discover other things. Thus, as a sketching method, the model helps the designer to revise and refine his ideas.

In the design world, digital programs are taking place instead of paper-based sketches. Parametric design programs can be thought as flexible in digital sketching. Because in parametric design programs, the designer can discover something in the digital sketch process that he didn't think before. This is due to the many forms of alternatives offered by the parametric design program. So, we can say that the design software also help designers to sketch.

Another common feature of model, paper-based sketch and digital sketch as a sketching method is that they have $3 \mathrm{D}$ features. Model is a direct $3 \mathrm{D}$ object. In paper-based sketch, the designer can draw 3D perspectives. Most software used as a digital sketch has a 3D feature.

\section{METHODOLOGY}

The infrastructure of the methodology in this study is based on the principle of 'learning by doing' (Fry et.al., 2009). Proceeded in architectural design studio concept and project critics were given (Kolb, 1984). In addition, it was found appropriate to conduct group work due to the limited elective course hours.

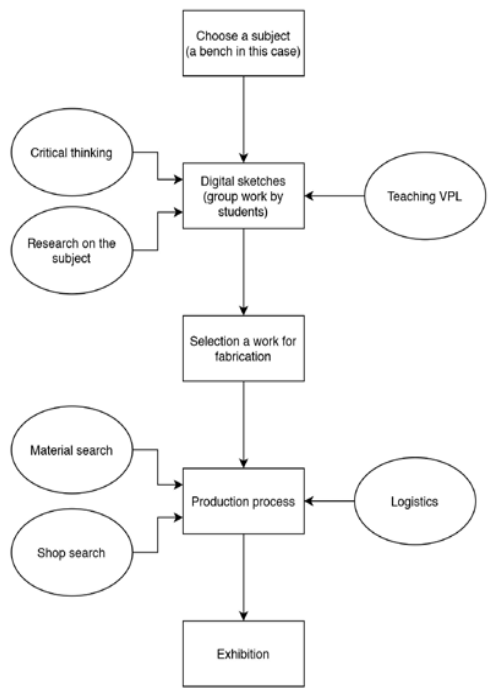

Figure 1: The methodology of the course
The progress in the course can be grouped as follows: 'choosing a subject', 'digital sketches', 'selection of a work for fabrication', 'production process' and 'exhibition' (Figure 1).

The elective course lasts 14 weeks. The course is 2 hours in a week. It is open to bachelor of architecture students. This term, 14 students registered to the course. Most of the students registered to this course were third or fourth year students. The students worked as groups at the first half ( 7 weeks) of the course. All of the students worked together as one group at the second half (7 weeks) of the course (Table 1).

Table 1: The course schedule

\begin{tabular}{ll}
\hline 1 week & Choosing a subject \\
\hline 6 weeks & Digital sketches process \\
& -Determination of groups (3-4 students in a group) \\
& -Research about the subject \\
& -Critical thinking/ brainstorming \\
& -Teaching/helping students about software \\
& -Submission and presentation of the proposals \\
\hline 1 week & Selection a work for fabrication \\
& -One of the group project is selected. \\
& -Revise model if necessary \\
\hline 3 weeks & Production process \\
& -Job distribution among group members \\
& -Material search \\
& -Logistics search \\
& -Shop search \\
& -Compare the prices \\
& -Revise model if necessary \\
\hline 2 weeks & Production process (continue) \\
& -Fabrication of the model \\
& -Logistic supply \\
& -Set-up camera for recording \\
& -Assembly the model \\
\hline 1 week & Exhibition \\
& -Test the product \\
& -Prepare a brochure \\
-Take photographs
\end{tabular}

\section{CHOOSING A SUBJECT}

Firstly, the content of the course and the process to be followed throughout the course have been explained to the students.

Afterwards, the subject to be designed within the course was determined with the students. The students were expected to present the design subject that they can fabricate. As a result, the students agreed with the idea that they could make a bench. Thus, in the case study, a 'bench' has been determined as the subject.

\section{DIGITAL SKETCHES}

The students determined their group members. Each group had 3-4 students. Followed by, the groups were asked to make digital sketches. The groups made initial sketches for a bench (Figure 2).

The groups brought variety of design alternatives for a bench. In this process, the groups used different types of software. For example, one group used SketchUp and a SketchUp plug-in for creation of Voronoi geometry. Another group used 3DsMax. The other two groups used Rhino and Grasshopper. 



Figure 2: Initial sketches by different group of students
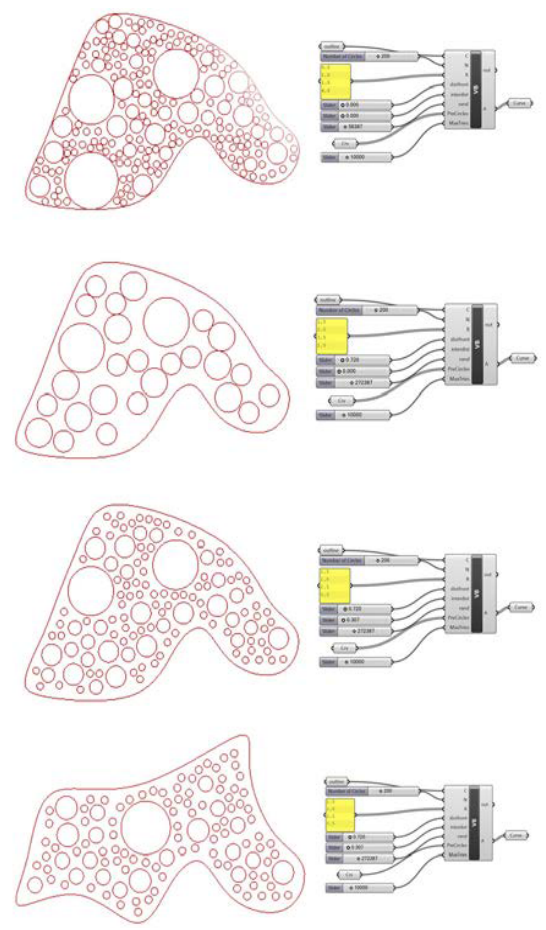

Figure 3: The sketches of the group who used 'circle packing' script
The students chose software for initial digital sketches according to their experience of the software. Most of the students felt very comfortable using SketchUp. However, most of them didn't feel comfortable using 3DsMax, Rhino and Grasshopper. Moreover, since the groups have 3-4 members, they helped each other for the use of the different software. For example, one student in the group was more experienced on the use of a specific software, on the other hand, another student had an expertise on another software.

After discussions between themselves and with the lecturer, they decided the software that they will use, and they presented their sketches accordingly. In this process, the lecturer of the course helped students on how they can model their designs in different modeling platforms.

Two groups used parametric design environments. In their design process, ready-made components and scripts were downloaded and studied with the students. Students developed their designs by benefiting from these scripts. In fact, students experienced parametric design thinking in this computer sketching process. In addition, the process of parametric design thinking (Oxman, 2017), which came with the use of parametric design tools, was tried being integrated to the process.

One group benefitted from 'circle packing' script for Grasshopper (Figure 3). This script creates a cluster of circles that have different sizes. The script has parameters such as circle sizes and distance between the circles. In addition to these parameters, students added other parameters to the script. For example, they added parameters such as 'extrude' and 'project'. In addition, they used Rhino for some other operations like 'booleandifference' and 'trim'.

The other group used a script that creates the object using the given reference lines, and it contours the object after creating it, and then extrudes the contour lines. After producing the object with the script, the students used 'bake' command. They also used commands in Rhino to create the details of the object. They modeled the sticks in Rhino to hold the sliced pieces of the object. Then they found the intersections using the 'booleandifference' command. So they created perforated slices (Figure 4). However, in order to adjust the distance between the slices, the additional pieces that they would place between the slices were required (Figure 7). They also modeled these pieces in Rhino. Then they saved all the parts in 2D in dwg format.

\section{SELECTION OF A WORK FOR FABRICATION}

Each group presented their designs. After this time, a model was chosen to be applied. While selecting the design for the application, the applicability criterion was taken into consideration.

'Sliced parametric bench' was selected for fabrication. After that, all students started working on this design. The thickness of the model had to be adjusted according to the material selection. In addition, the measurements of the intermediate parts and the sticks had to be adjusted again. These alterations were made simultaneously with the decisions regarding material selection. 




Figure 4: First sketches of the 'sliced parametric bench'

\section{PRODUCTION PROCESS}

After selecting the model for the application, the fabrication processes started to be examined by the class. The students mainly searched for materials, prices, shops and logistics. They made job distribution among themselves.

In this process, students have determined the material that they will use in fabrication. They researched the material prices. For the cutting of the materials, they have determined the shop that they will go to. For this, they first got the price from many different shops. Finally, they decided on one.

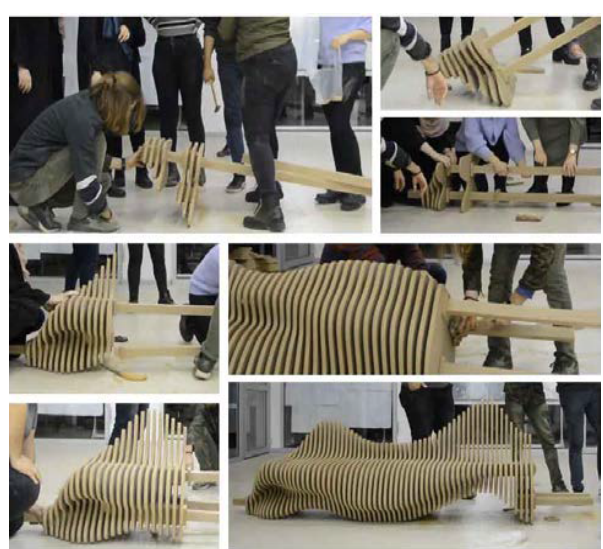

Figure 5: Production process
After the parts were produced in the shop, the parts were brought to the university to be combined. The assembly process was done together. This assembly process has been recorded (Figure 5) (Parametric Bench, 2019).

\section{EXHIBITION}

Finally, the bench was exhibited in the university and was decided to be used as permanent furniture (Figure 6 , Figure 7). In addition, the students wrote their names on each slice prior to fabrication as scoring to leave the names permanently (Figure 8). The bench is durable. People regularly use it (Figure 9).

\section{STUDENTS' PERSPECTIVE}

The lecturer of the course asked students to write their opinions in one or two sentences about this parametric bench experience. 10 students wrote their opinions. It seems that students satisfied by producing a ready-to-use product. Also, they were glad that they have experienced a collaborative work. The opinions of the students are listed below.

- "I felt that architecture wasn't just about drawings." Banu Agca

- "I always thought it was very difficult to work with a large group. But, with this project, I learned that some things cannot be done alone, and being together is very valuable." Ayse Nur Turan

- $\quad$ "Fabrication of our design work is the best power of our profession we will have." Merve Vapurcu.

- "Difficulties, exchanges of ideas, teamwork and a product... These are the best parts of the design process." Sena Aslan

- "Within the scope of this course, we created a parametric design product. The important achievements were to experience digital design in a controlled manner, to work in coordination with the team and to create a product." Sena Sarioglu

- "Not using the technological design tools is like communicating with telegraph instead of telephone." Muhammet Bilgic

- "This was my first $1 / 1$ scale work. I learned more about the material and joint details." Sena Nur Cokca

- "I saw that various designs can be made with the help of computer programs." Gunay Elif Cetingul

- "I am very happy to be part of this work and I am happy that we add liveliness to a space by designing a product." Fatma Zehra Kurtis

- "I have seen that parametric design causes different reactions in people. With the design we made today, I saw that we broke certain patterns that everyone thought of as benches. I can say this, because I have the opportunity to watch the first reaction of the people who see it. When people came across a different bench design, they surprised, and they examined the bench." Hakan Canik

\section{RESULTS}

An important output in this study was the production of the design that the students modeled in Grasshopper as part of the undergraduate elective course. Thus, students were able to experience processes from design to fabrication.

One of the other important outputs in this process was that students learned to make a group work. In this process, they made a job distribution among themselves. For example, one brought a nail while the other brought a hammer. One brought the cut pieces from the shop to the university while the other brought the camera. Another brought a tripod. 


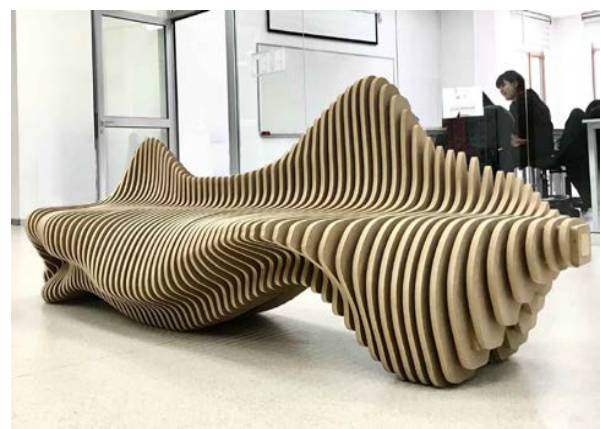

Figure 6: Parametric bench

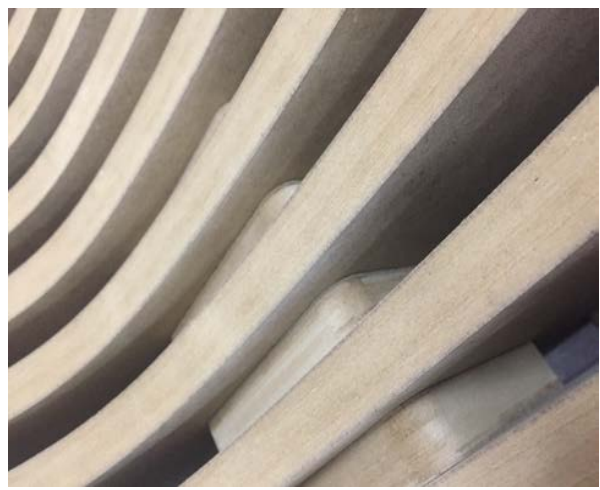

Figure 7: Detail of the extra pieces

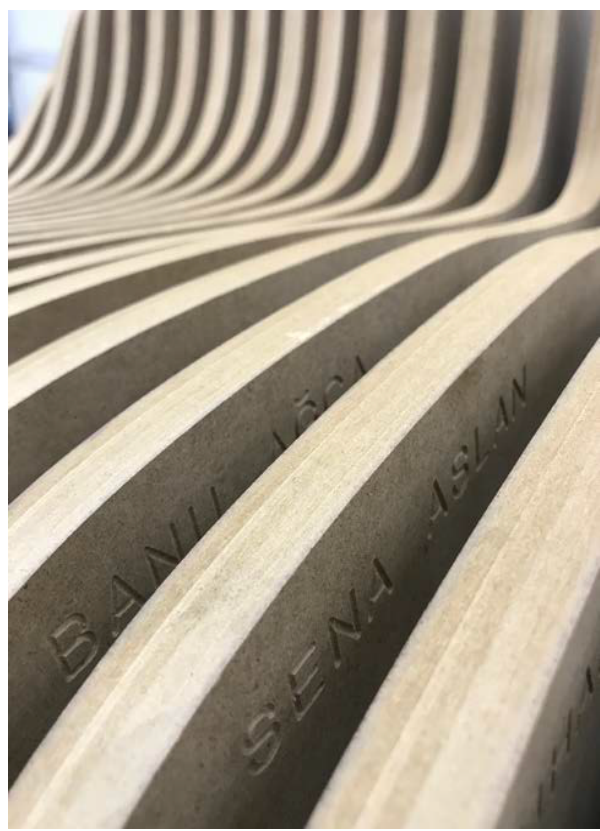

Figure 8: Detail of the sign of the student's names
In addition, students learned to think together with the material. For example, they have modeled in Grasshopper according to the material thickness. Thus, students experienced the versatile thinking throughout the design process.

In the initial sketching stage, the groups of students proposed variety types of bench. In this process, the groups used different types of software. It can be said that the initial design proposals have an effect of the computer software which have been used for digital sketches. For example, the design proposal of one group, in which 3DsMax has been used, had blobby effect. Moreover, the design proposal of another group, in which SketchUp plug-in designed to create Voronoi forms has been used, had obvious effect of the plug-in. In addition, the other two design proposals, in which Rhino and Grasshopper have been used, had effect of the used scripts. It is also important to note that this effect can depend on other parameters such as student's expertise on the software.

Parametric bench has been turned into a bench by combining the parts where it is planned to be located. However, if it is wanted to be moved to another place, extra logistics will be required due to its weight or parts will have to be disassembled and reassembled. If a more portable bench is desired, it would be ideal to leave gaps in the sliced pieces. Or a lighter material may be preferred.

\section{DISCUSSION}

With the methodology determined in this study, students were able to experience the mentioned outcomes in an elective course. It is thought that it is possible for students to make this type of production within the scope of a 2hour elective course per week with the methodology produced in this study.

Since the ready-made scripts have already designed geometries in the first place, the beginner students may be affected from the initial geometries that the scripts give. However, if the parameters in the script are more than two or three, the script can lead the students to sketch more freely, so it can contribute to student's creativity.

The creativity of the student will likely be affected by the expertise in the use of parametric software. When the student starts to manage the script (such as adding new components to the written script or creating his own script from scratch), he will start to involve in parametric design thinking, which requires thinking design intentions, geometrical transformations and coding simultaneously.

It should be noted that this course is limited by a furniture design. Therefore, there are no various constraints in this design. But there will be various constraints (such as structure, space relations, acoustics) that need to be handled in architectural design. This will make the process more complicated 


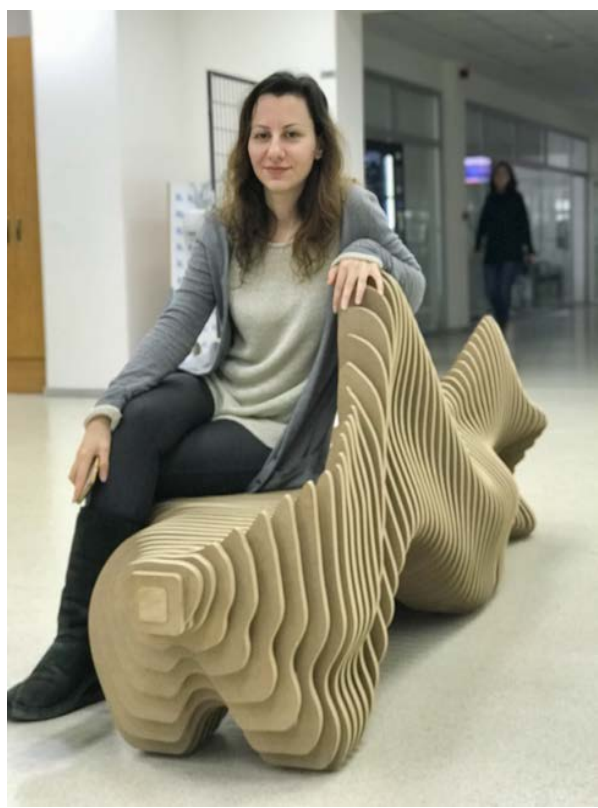

Figure 9: The bench is in use

\section{ACKNOWLEDGEMENTS}

The students involved in parametric bench study are as following: Muhammet Bilgic, Sena Aslan, Hakan Canik, Ayse Nur Turan, Emine Zulal Ozturk, Fatma Zehra Kurtis, Onur Ozden, Ali Kozali, Seyma Bolukbasi, Banu Agca, Sena Nur Cokca, Gunay Elif Cetingul, Merve Vapurcu and Sena Sarioglu.

\section{REFERENCES}

Agirbas, A. (2018). The Use of Metaphors as a Parametric Design Teaching Model: A Case Study. Design and Technology Education: an International Journal, 23 (1), 4054.

Aish, R. \& Hanna, S. (2017). Comparative evaluation of parametric design systems for teaching design computation. Design Studies, 52, 144-172.

Bhooshan, S. (2017). Parametric design thinking: A case-study of practice-embedded architectural research. Design Studies, $52,115-143$

Celani, G. \& Verzola Vaz, C.E. (2012). CAD Scripting and Visual Programming Languages for Implementing Computational Design Concepts: A Comparison From A Pedagogical Point Of View. International Journal of Architectural Computing, 10, 121-138.

Cross, N. (1982). Designerly ways of knowing. Design Studies. $3(4), 221-227$.
Cross, N. (2006). Designerly Ways of Knowing. London: Springer.

Cross, N. (2011). Design Thinking. Oxford-New York: Berg.

Do, E.Y.L., Gross, M.D., Neiman, B. \& Zimring, C. (2001). Intentions in and relations among design drawings. Design Studies, 21 (5), 483-503.

Fry, H., Ketteridge, S. \& Marshall, S. (2009). A Handbook for Teaching and Learning in Higher Education: Enhancing Academic Practice. London: Taylor and Francis group.

Garner, S. (1992). The undervalued role of drawing in design. In D. Thistlewood (Ed), Drawing research and development (pp. 98-109). London: Longman.

Goel, V. (1992). III-structured Representations for III-structured problems. In Proceedings of the Fourteenth Annual Conference of the Cognitive Science Society, Hillsdale, NJ: Lawrence Erlbaum.

Goel, V. (1995). Sketches of thought. Cambridge, MA: MIT Press.

Goldschmidt, G. \& Smolkov, G. (2006). Variances in the impact of visual stimuli on design problem solving performance. Design Studies, 27(5), 549-569.

Gross, M. \& Do, E. Y. (1996). Ambiguous intentions: A paper-like interface for creative design. In Proceedings of the ACM UIST Conference (pp. 183-192).

Kolb, D.A. (1984). Experiential learning: Experience as The Source of Learning and Development. Englewood Cliffs, $\mathrm{NJ}$ : Prentice Hall.

Oxman, R. (2017). Thinking difference: Theories and models of parametric design thinking. Design Studies, 52, 4-39.

Parametric Bench. (2019). The assembly process of the bench https://youtu.be/IB8smOqhKcs (Accessed at 22 September 2020).

Schnabel, M. A. (2012). Learning parametric designing. In Gu, N. and Wang, $X$. (Eds), Computational Design Methods and Technologies: Applications in CAD, CAM and CAE Education (pp. 56-70). Hershey: IGI Global.

Schon, D. A. (1983). The Reflective Practitioner: How Professionals Think in Action. New York: Basic Books.

Schon, D. A. (1987). Educating the Reflective Practitioner: Towards a New Design for Teaching and Learning in the Professions. San Francisco: Jossey-Bass Publishers.

Schon, D. A. (1988). Designing: Rules, types and worlds. Design Studies, 9, 181-190.

Schon, D.A. \& Wiggins, G. (1992). Kinds of seeing and their functions in designing. Design Studies 13(2): 135-156.

Suwa, M. \& Tversky, B. (1996). What architects see in their sketches: implications for design tools. In Proceedings of CHI'96 (pp. 191-192). Vancouver, Canada.

Suwa, M. \& Tversky, B. (2002). How do designers shift their focus of attention in their own sketches? In M. Anderson, B. Meyer, \& P. Olivier (Eds.), Diagrammatic reasoning and representation (pp. 241-254). London: Springer. 